\title{
Ideas Sharing Through ICT in Innovation Processes: a Design Theory for Open Innovation Platforms
}

\author{
Barbara Aquilani ${ }^{1}$, Tindara Abbate $^{2}$, Alessio Maria Braccini ${ }^{1}$
}

\begin{abstract}
Since Henry Chesbrough's remark on the importance of opening innovation processes to the cooperation of external entities, like partners, competitors or customers, open innovation gained momentum. Open innovation approach was started and run by different companies around the world. Meanwhile specific platforms were developed to support these processes, either by intermediaries aimed at helping companies to shift to an open innovation approach, or by firms which decided to adopt this approach trough their own created and managed platforms. Through a descriptive design theory perspective the paper analyzes the features (components) that these web-based platforms offer in respect to the requirements they have to fulfill in order to effectively support the open innovation approach.
\end{abstract}

Keywords. Open Innovation, Software Platforms, Design Research, Exploratory Design Theory

\section{$1 \quad$ Introduction}

In the past, firms believed that through investing in their critical R\&D activities more strongly than their competitors and protecting their intellectual property, they could innovate more rapidly and radically and, therefore, sustain their competitive advantage in the long run. This model of innovation, later defined closed innovation, was challenged by the reduction of time to market for a larger number of products and services, the mobility of knowledge resources, and the growing availability of private venture capital [1]. In this landscape, a new innovation approach, called open innovation (OI), arose. In OI perspective, firms are increasingly opening up their internal R\&D departments and innovation processes to external parties. This innovation approach seems to be an attractive alternative to improve innovativeness and competitiveness [1]. Firms strongly interact and collaborate with external partners, such as suppliers, customers, competitors research organizations, with the aim of foster-

${ }^{1}$ Barbara Aquilani, Alessio Maria Braccini

Dipartimento di Economia e Impresa, Università degli Studi della Tuscia, Viterbo, Italy, \{b.aquilani|abraccini\}@unitus.it

2 Tindara Abbate

Dipartimento di Scienze Economiche, Aziendali, Ambientali e Metodologie Quantitative, Università degli Studi di Messina, Messina, Italy, abbatet@unime.it. 
ing and sustaining innovation processes and, thus, enhancing their performance [1]. To support OI processes and primarily to cooperate with external actors who are in the position of sharing ideas, organizations make use of software platforms created by innovation intermediaries that help in transferring and sharing ideas among different parties not directly linked and rarely networked [2, 3]. Also, several multinational companies, like P\&G, Ducati, Volvo and Nokia implemented their own software platforms to capture innovative ideas, to build new products/brand, or to improve existing products. Within these platforms the interactions among actors span across one-way exchanges to on-going and continuous dialogue, useful to create and develop innovative solutions to market needs [4].

In this paper we focus on the OI software platforms with a design research perspective. Since OI is frequently adopted as an innovation model [1], and software platforms are commonly used to support the idea sharing [4], there is the need of theories that clarify how to design such platforms. To this regard the paper analyzes both OI processes and OI platforms to propose a first explanatory design theory for OI platforms. We discuss literature on OI and related software platforms to derive requirements and components of the design theory. The paper is structured as follows. After the description of the research design in section 2, both the OI process and the most frequently used software platforms are discussed in section 3. The exploratory design theory is proposed and discussed in section 4. Final thoughts and remarks on future research steps conclude the paper in section 5.

\section{Research Design}

As described in the introduction, this paper adopts a design research perspective and aims at defining a design theory for OI platforms that states the designing principles for a software platform supporting OI efforts. A design theory is an outcome of a design research effort [5, 6]. According to Walls et al. [5] a design theory is composed by: (a) a design product, and (b) a design process. The design product is in turn composed by: metarequirements, meta-design, kernel theories, and a set of testable design hypothesis. The design process is instead composed by the design method, the kernel theories, and a set of testable design process hypotheses. A cleaner specification of a design theory is provided by Gregor and Jones [7] and is based on: kernel theories, metarequirements, meta-design, design method, and testable design product/process hypotheses. Both frameworks assign to kernel theories the core of a design theory. They are the necessary justificatory knowledge that informs the design process. The kernel theories allow researchers to formulate prescriptions for the other elements of a design theory. 
Since in this paper we specifically intend to focus only on the artifact we find the contribution of Baskerville and Pries-Heje [8] more helpful to this regard. These authors distinguish between practice theory and explanatory design theories. The first are prescriptive theories, which provide prescriptions on how specific artifacts shall be designed. Explanatory design theories explain instead why a generalized set of requirements is satisfied by a generalized set of object components. The essence of an explanatory design theory can be captured by representing the general requirements, which can be conditions or capabilities, the general components, and the relationships between the two [8].

Given the aim of this paper we propose an explanatory design theory that describes the functionalities that shall be found in a software platform to support OI organizational efforts. To this regard the requirements of such a platform are identified with reference to the literature on OI, which clearly describes the processes that organizations run when they approach open innovation. For the components, the most common platforms for OI are analyzed and discussed in the paper.

\section{Open Innovation: Process and Software Platforms}

The work of Chesbrough [1] highlights that "open innovation is paradigm that assume that firm can and should use external ideas as well as internal ideas, and internal and external path to market as firm look to advance their technology". The preeminent idea concerns opening up the innovation process outside the traditional boundaries of organizations [1], claiming a higher involvement of external actors in their innovative activities. Organizations cannot merely innovate in their internal R\&D functions, but they have to encourage the interaction with their environment and integrate resources and competences derived by external entities to create different opportunities for product development, to exploit new ideas, to meet market demands and, consequently, to stay abreast of competition [1,9]. External actors can include: customers, suppliers, experts, universities, private/public R\&D institutions, partners, competitors, and the general community as a whole.

Consequently, the boundaries of the organizations become porous and permeable, allowing innovative ideas to flow selectively inside and outside [1]. Innovation is getting though more global in nature and is shared among several actors characterized by different expertise and professional experience. The exchange of ideas and the cooperation allow enriching firm's knowledge on a long-term basis and improve its ability to get in touch with other subjects, firms and organizations [10]. Also, such collaboration with different subjects is becoming necessary to increase and sustain a company’s innovativeness [11], to reduce time to market for products/services, and to shrink costs connected to innovation. 
Therefore, the OI paradigm challenges the ways to understand innovation. The traditional model is overly linear, sequential and defined by firms that invest in their research labs and in their internal product development processes without any form of interaction with other external forces. The R\&D function, traditionally considered critical for innovation, is based on vertical integration logic, through which the firm realizes any aspect of a business. On the contrary, the OI model stresses the concept that innovation process must be more extended, collaborative, and engaged with a wider variety of external participants, combining internal and external ideas into useful contexts, suitable systems, and architectures [12].

\subsection{The Open Innovation Process}

The opening up of the innovation processes concerned many industries such as pharmaceutical (e.g., Bayer, Pfizer) and biotechnology, software (e.g., Apple, IBM), electronics (e.g., Philips with OI park), high-tech, sports, and food. Both large multinational and small-medium sized firms are engaged in these OI endeavours and in iterative and interactive probe-and-learn processes [13].

Literature identifies three important core processes in OI: outside-in, inside-out and coupled process [14]. In the outside-in process companies improve their own knowledge through the use of a broad range of external ideas, emphasizing the relevance and the role of dense networks of innovation, the forms of customer integration and the use of third parties that facilitate interactions among different subjects using OI platforms [14].

In the inside-out process companies are oriented to external exploitation of their internal knowledge by carrying out ideas to market, selling intellectual property rights (IPR), licensing mechanisms, and bringing technologies to the outside environment. In other words, this core process aims at allocating and commercializing externally ideas and technological innovation derived by firms' internal R\&D activities [14].

In the coupled process the concept of co-creation with complementary partners is relevant, stimulating the definition of forms of cooperation and collaboration with these subjects operating in different sectors of activity and having specific interests [14]. These external and complementary partners can offer ad hoc solutions that can improve the company's innovations, or they can exploit solutions developed by the company itself [14]. In addition, these forms of collaboration require strategic decisions, based on the features, the role of involved actors or groups of organizations in the OI networks, and the activities to maintain heterogeneous partner base over time [14].

Many scholars studied OI processes identifying a different number of stages characterized by various activities $[15,16]$. These stages demand for both strategic and operational decisions, to define and to manage innova- 
tive collaborative projects. Among them, it is possible to include: opportunities seeking to explore internal/external ideas; analysis and evaluation of their market potentiality and inventiveness; evaluation of opportunities linked to the intermediaries' involvement; recruitment of potential developments partners; value capture by commercialization of ideas and technologies brought to the market, and, the innovation proposals extensions to the formal/informal network. However, these activities, in general, and the exchange of ideas and collaboration with different partners (across different contexts and backgrounds), in particular, are not straightforward and characterized by some codifying difficulties. To this regard, Lee et al. [17]suggest the use of the intermediated network model in which the intermediary organizes and manages the network oriented to create both high involvement and trust among different participants.

Defined commonly as organizations that operate as "agent or broker in any aspect of the innovation process between two or more parties" [3], innovation intermediaries can offer different benefits not only to smaller firms, which face many difficulties connected to the opening up of their innovation processes, but also to larger organizations, especially for outbound OI [3, 18-20]. Applied in several ways and across different domain areas, these organizations play a significant role in facilitating the innovation processes, assisting customers to effectively catch the opportunities of customer's business models, connecting innovation requests with potential, globally distributed, innovation providers (e.g., researchers, lead users), creating and maintaining innovation networks and, finally, facilitating outward and inward innovation results technology commercialization. The main functions, performed by these intermediaries, can be seen as coupled to the diverse phases of the innovation process: (a) the search for innovation stage contains some functions as, for instance, partners identification, suppliers selection, and alternative options evaluation; (b) the innovation transfer step includes other functions, such as: support to deal making, packaging of technology, innovation adaptation to users' needs.

In addition, these intermediaries have been able to change the R\&D department and activity configurations for many companies, government agencies, and non-profit actors by using their price-based method to involve innovators from around the world. They enable firms to source (as well as to exploit) innovation globally with limited investments in proprietary structures, reducing the associated transaction costs and information asymmetries through a broad availability of information.

\subsection{Open Innovation Software Platforms}

Open Innovation Intermediaries (OII) emerged as OI platforms that stimulate, support, and develop innovation communities through interconnected networks of people globally distributed. Some examples of OII are: 
Ninesigma, Innocentive, IdeaConnection, Big Idea Group, Yet2.com, Mercatodellinnovazione, etc. The OII are able to build and maintain efficient bridges between seekers (companies that seek at and try to solve innovation problems or to take advantages of business opportunities), and solvers (scientists, professionals, post-graduate students, highly qualified individuals around the world), which are potentially able to find innovative solutions [21], or buyers and sellers of intellectual properties. Through the Internet and online web 2.0 tools, these OI platforms promote and facilitate collaborative innovation forms, sustain worldwide R\&D projects, and intensify interactions among subjects in a significant and on-going dialogue to explore new solutions. Every day, Internetbased platforms help individuals and organizations across the globe to cross-fertilize their resources and competences in a wide variety of specialized fields.

Created by both intermediaries of innovation or generated by large multinational companies, the platforms show some interesting characteristics[22]: a) collaboration, facilitating different forms of collaborations between seekers and solvers and stimulating online-communities that involve different subjects as appreciated solvers; b) interactivity, sharing information between seekers and solvers; c) networking, in terms of scanning and establishing connections in a network for identifying innovative solutions that meet seeker's requests and other potential needs; d) articulation, providing different and clear sections that facilitate search of information by users; e) accessibility, defining search link and screens that can facilitate experiences on the web site; f) multimedia, offering various and efficient web 2.0 tools (e.g., blog, community, forum, etc.) oriented to stimulate suitable relations among participants; g) groups formation, concerning the creation of a special group of experts for solving problems posted on the platform. With one or more useful characteristics, these Internet-based platforms enable and support open networking of individuals and organizations that move from a closed to an OI approach [22].

\section{The Proposal of an Exploratory Design Theory}

Following the considerations on the literature on OI and OI platforms, this section proposes an explanatory design theory for OI platforms, which is shown in Fig. 1. Following Baskerville and Pries-Heje [8], the theory is decomposed into requirements and components. 


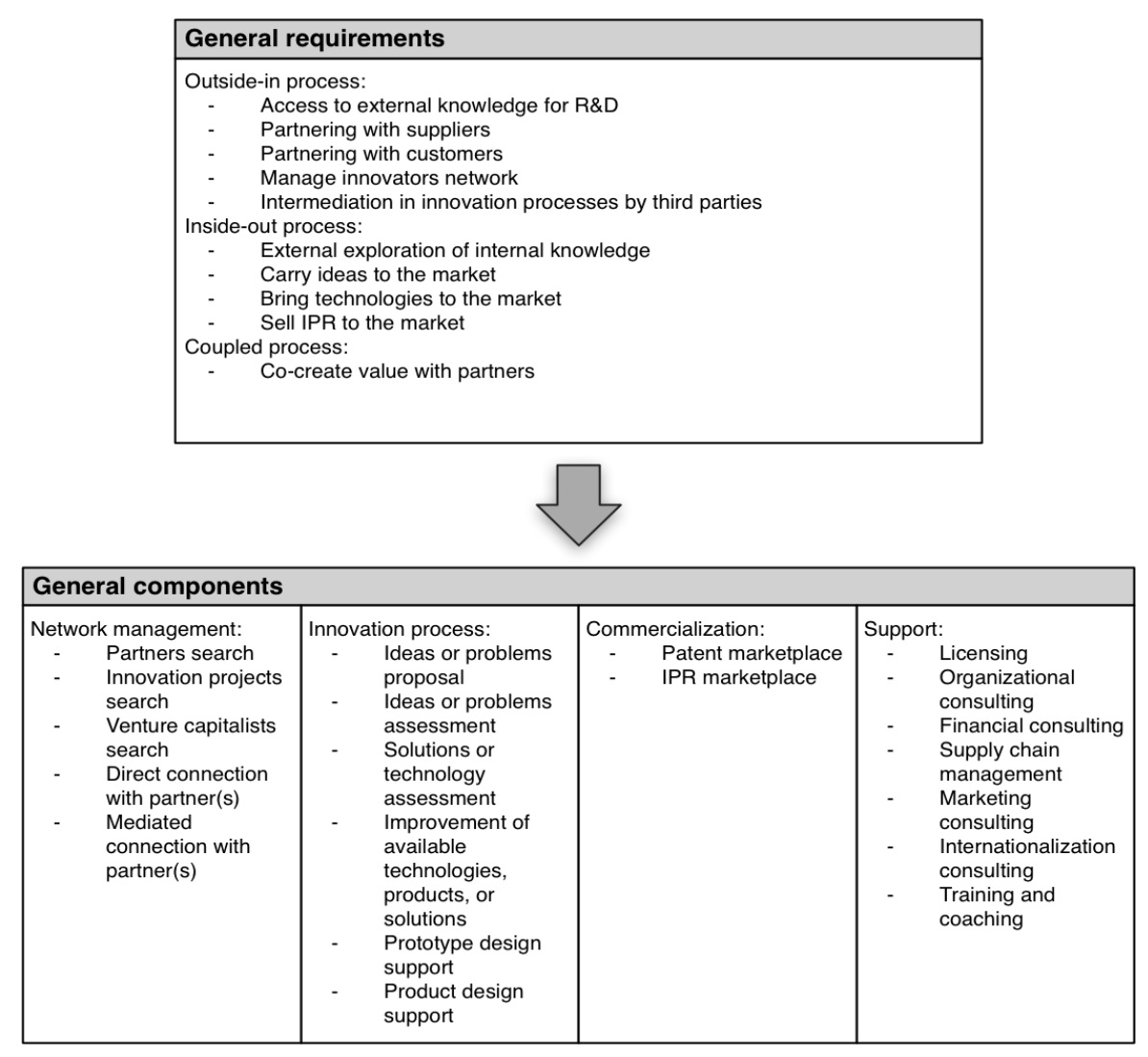

Fig. 1. Explanatory design theory for OI platforms

The literature shows how the OI process presents itself in different flavors according to the decisions of the organization that is opening up its processes for cooperating with external partners. Different stages of the innovation process (i.e. importing innovation from outside, exporting innovation to the external environment, coinnovate with partners) involve different sets of activities. Since several organizations might choose to perform OI in different ways, we argue that a design theory for OI platforms shall contemplate modularity. We found some difficulties in representing this concept, which is basic in software design and development, into the explanatory design theory blueprint, since it seems not to have been taken into account until now. Therefore, we separated our general requirements and components into groups, each one representing the different ways in which organizations might perform OI (requirements), and the different set of features (components) that a platform to support OI shall integrate to be effective.

On the requirements side, we resorted to Enkel's et al. [14] three different processes: outside-in, inside-out, and coupled. Since each of these processes focus on different aspects of OI, requirements are certainly differentiated. In all processes, the ability of the organization to enter in contact with valuable partners is crucial. Network management components in the supporting platforms shall therefore be able to sustain the organization in 
partners/innovation projects search, in establish and manage the connections, either directly or through intermediaries.

Ideas exchanges are at the core of OI in general, and more specifically are crucial in the outside-in (where ideas are searched externally) and inside-out (where internal ideas are made accessible externally) processes. On the components side the support of the core of OI process requires the platform to be capable of addressing problems/ideas/solutions management (i.e., proposals, discussion, and approval) (i.e., NineSigma, Innocentive, Yet2.com, Mercatodell'innovazione). Product and prototype solutions support are particularly useful in joint efforts (coupled processes) of partners, which aim at co-creating value (i.e., Big Idea Group, Innocentive).

Commercialization happens only when specific IPR elements are sold externally to the market. This happens usually in inside-out processes, when the organization wishes to sell its internal knowledge on the marketplace. On the platform side, at this stage, specific commercialization support components are necessary (i.e., Inpama, Yet2.com, Mercatodell'innovazione).

Finally existing platforms for OI show the presence, in some cases, of supporting/consulting services (i.e., NineSigma, Big Idea Group, Inpama) [22], which are normally accessible to the organization wishing to adopt OI. These services are more traditional consulting services offered by a third party professional organization that might help, in specific aspects, the willing open innovator. In this case, on the components side, the role of the supporting platform is just the provision of information sources necessary to advertise these consulting services (which are most probably human-based). For example, Big Idea Group intermediary proposes several consulting services related to technological-technical aspects, marketing strategies and finance [22]. It also answers to specific needs of the seeker organization, offering useful personalized solutions, through its interface and its specialized personnel. In some cases (depending on the service), the platform shall also be able to let the open innovation company access these services (i.e., NineSigma).

The proposed explanatory design theory is therefore composed of four different set of requirements (or modules). The core is composed by the set of requirements that support the whole innovation process. The networking requirements are also relevant as they shall support the organization in building the network of relationships with partners. Finally, the commercialization components are expected to be in the platform only in the case of an inside-out-project. 


\section{Conclusion}

This paper aims at proposing an explanatory design theory for open innovation platforms. Through the discussion of literature on OI, the paper identifies both the general requirements and the general components based on the three specific processes of the OI approach. The main contribution of the paper is the definition of a first canvas to help both OII and firms willing to create their own OI platform, to effectively build and manage this web-based interactive tool. This first insight is still at an exploratory effort and deserves refinements that will be tackled in future research efforts. Besides proposing this explanatory design theory, the paper suggests the need for exploratory design theories to be able to contemplate modularity, which is a basic concept in software development.

Obviously, the selected processes to be run on the OI platform as well as the different weights firms and/or OII assign to processes to be implemented on them, impose also requirements on the necessary resources and on their distribution among the different processes to be realized. The exploratory design theory we propose here is anyhow not focusing on this aspect, which instead results as an implication for its use.

\section{References}

1. Chesbrough, H.W.: Open Innovation: the new imperative for creating and profiting from technology. Harvard Business School Press, Boston (2003).

2. Hargadon, A., Suton, R.: Technology Brokering and Innovation in Product Development Firm. Adm. Sci. Q. 42, 716-749 (1997).

3. Howells, J.: Intermediation and the Role of Intermediaries in Innovation. Res. Policy. 35, 715-728 (2006).

4. M., S., G., V., E., P.: Collaboration to Create: the Internet as a Platform for Customer Engagement in Product Innovation. J. Interact. Mark. 19, 4-17 (2005).

5. Walls, J.G., Widermeyer, G.R., Sawy, O.A. El: Assessing Information System Design Theory in Perspective: How Useful Was our 1992 Initial Rendition? J. Inf. Technol. Theory Appl. 6, Article 6 (2004)

6. Braccini, A.M., Federici, T.: New Internet-based Relationships Between Citizens and Governments in the Public Space: Challenges for and Integrated System Design. In: Baskerville, R., De Marco, M., and 
Spagnoletti, P. (eds.) Designing Organizational Systems. An Interdisciplinary Discourse. pp. 157-180. Springer, Berlin, Heidelberg (2013).

7. Gregor, S., Jones, D.: The anatomy of a design theory. J. Assoc. Inf. Syst. 8, 312-335 (2007).

8. Baskerville, R., Pries-Heje, J.: Explanatory Design Theory. Bus. Inf. Syst. Eng. 2, 271-282 (2010).

9. K., L., J., S.A.: Open for Innovation: The Role of Openness in Explaining Innovation Performance among UK Manifacturing Firms. Strateg. Manag. J. 27, 131-150 (2006).

10. Koschatzky, K.: Networks in Innovation Research and Innovation Policy - An Introduction. In: K., K., M., K., and A., Z. (eds.) Innovation Networks: Concepts and Challenges in the European Perspective. Physica Verlag, Heidelberg (2001).

11. K., D., F., P.: The Market for Open Innovation: Increasing the Efficiency and Effectiveness of the Innovation Process. (2010).

12. Chesbrough, H.: Open Innovation: Where We've Been and Where We're Going. Res. Manag. 55, 20-27 (2012).

13. S., L.G., G., M.J., S., P.A.: Marketing and Discontinuous Innovations: The Probe and Learn Process. Calif. Manage. Rev. 38, 8-37 (1996).

14. Enkel, E., O., G., H., C.: Open R\&D and Open Innovation: Exploiting the Phenomenon. R\&D Manag. 39, 311-316 (2009).

15. J., F.T., D., F.: Managing Open Innovation in Biotechnology. Res. Technol. Manag. 49, 14-18 (2006).

16. S., H., M., E., N., K., H., O.: How Can Software Support Open Innovation? Extending Community and Marketplace Perspective. Int. J. Netw. Virtual Organ. 10, 1-17 (2012).

17. S., L., G., P., B., Y., J., P.: Open Innovation in SMEs - An Intermediated Network Model. Res. Policy39. 39, 290-300 (2010).

18. Abbate, T., R., C.: Knowledge Sharing and Innovation: the Contribution of Innovation Intermediaries. In: Marco, M. De, Te'eni, D., Albano, V., and Za, S. (eds.) Information Systems: Crossroads for Organization, Management, Accounting and Engineering. pp. 251-258. Physica Verlag, Heidelberg (2011).

19. S., N., M., S.: A Buyer's Guide to the Innovation Bazaar. Harv. Bus. Rev. 85, 109-118 (2007).

20. L., H., N., S.: Connect and Develop Inside Procter and Gamble New Model for Innovation. Harv. Bus. Rev. 58-66 (2006). 
21. H., C.: Open Business Models: How to Thrive in the New Innovation Landscape. Harvard Bus. Sch. Press. (2006).

22. Aquilani, B., Abbate, T.: Gli Open Innovation Intermediaries: la Propsettiva dei Seekers. Proceedings XXV Convegno Annualedi Sinergie., Ancona (2013). 